\title{
Occupational exposure to sharps and splash: Risk among health care providers in three tertiary care hospitals in South India
}

\begin{abstract}
Occupational exposure to blood and body fluids places Health care providers at risk of infection with blood borne viruses including HIV. To understand Health Care Providers' $\left(\mathrm{HCP}^{*}\right)$ perception of risk of occupational exposure to needles, blood and body fluids, to find out the correlates of exposure and to identify groups of HCP at high risk of sustaining maximum number of such exposures. A cross sectional survey was conducted on HCP in three tertiary care hospitals in Kerala, between August $20^{\text {th }}$ and October $30^{\text {th }}, 2004$ Chi square test, independent-sample T test and one-way ANOVA was used for analysis. Overall, $74.5 \%(95 \% \mathrm{Cl} 71.3$ to 78.2$)$ of the respondents were exposed at least once in the last 12 months. Surgeons were exposed most frequently, with a mean of 3.8 injuries per person per year. Injection needles were responsible for $68 \%$ of the injuries. Those who underwent the in-service training program on needle safety were less injured $(P=0.001)$. Only $4 \%$ of surgeons had undergone needle safety training. Almost half the surgeons, anesthetists and medical students did not know the reporting procedure and only $10 \%$ of anesthetists knew about the provision of Post Exposure Prophylaxis (PEP). A considerable proportion of respondents $(85 \%)(95 \% \mathrm{Cl}$ 81.2 to 88.5 ) were concerned about acquiring blood borne infections and $90 \%$ were immunized against Hepatitis B. Training of Health care providers is absolutely essential for injury reduction and should take into account the varying incidence of exposure across different occupation groups.
\end{abstract}

Key words: Sharps, splash, occupational exposure, post exposure prophylaxis

\section{INTRODUCTION}

Occupational exposure to blood and body fluids places HCP at risk of infection with blood borne viruses including Human Immunodeficiency Virus (HIV) ${ }^{[1]}$ The World Health Report 2002 estimates that $2.5 \%$ of HIV, $40 \%$ of hepatitis B (HBV) and hepatitis $\mathrm{C}$ (HCV) cases among HCP worldwide are the result of occupational exposure. ${ }^{[2]}$ The transmission of HBV, HCV and
HIV has been related to frequency of exposure and effectiveness of post exposure management, ${ }^{[3]}$ Most people at risk for occupational exposures are in developing countries where there is a paucity of standard reporting protocols ${ }^{[4]}$ and most exposures are caused by sharps. ${ }^{[2]}$

Anonymous hospital surveys indicate that over one-third of exposed HCP do not report needle stick injuries, so the rate of injuries and the number of infected individuals may be much higher than that reported. ${ }^{[5]}$ We undertook this study to find out the extent of occupational exposures among HCP in one state in India.

\section{MATERIALS AND METHODS}

\section{Sampling frame and method}

A cross sectional survey was conducted among a selected group of HCP posted in surgery departments, who were expected to be at high risk of occupational exposures in three tertiary care hospitals in Trivandrum. These groups were surgeons, anesthetists, nurses, nursing students and final year medical students. The study population was listed first by the institutions and then by occupation. The questionnaire was to be distributed to all the individuals in each occupational group present between August $20^{\text {th }}$ and October $30^{\text {th }}$ 2004 (the study period).

\section{Survey instrument}

An anonymous, structured, selfadministered questionnaire, adapted from $\mathrm{CDC}^{\left[{ }^{[6]}\right.}$ printed in English was pre-tested and used as the data
S. Tetali,

P. L. Choudhury Achuta Menon Centre for Health Science Studies, Public Health wing of Sree Chitra Tirunal Institute for Medical Sciences and Technology, India

For correspondence: S. Tetali,

MLR-2, Mangalam Lane,

Sasthamangalam, Trivandrum-695010, India. E-mail: shailaja_c@yahoo.com . 
collection instrument. The questionnaire was divided into 3 sections: section one had questions on perception of risk of exposure to sharps and splash. Section two had questions on the exposure and section three had questions on post exposure prophylaxis. In addition to demographic characteristics, the questionnaire contained items about the following independent variables:

Experience in direct patient care (in years), perception of risk (On a 3-point scale), availability of personal protective equipment, training, details of exposure and post exposure. Perception of risk included questions on correction of problems that increase the risk of sharp injuries once they are brought to hospital authority's attention. Perception was also studied by asking about their belief if needle injuries are avoidable. There were questions on the availability of containers for safe disposal, availability of disposable syringes and gloves. The items on training were specific only to the training in the current hospital, responses on previous training were not elicited.

The next set of questions was on occupational exposure. For example, "In the last 12 months, did you sustain injury by a sharp object that was previously used on a patient" (responses were yes, no), "if yes, how many times were you injured?" Similarly, questions were asked about exposure to splash.

Questions on circumstances of injury pertained to the type of sharp instrument that caused the injury, the activity leading to injury and the place of injury. All these had forced options. Other questions about exposure were about whom they would contact if exposed and reasons for not reporting the exposure (both had forced options) There was one question each about respondents' immunization status with respect to Hepatitis $B$ and his/her concern for blood borne infections. The last set of questions was on post exposure events- knowledge about availability of testing and treatment in their hospital.

The authors pre-tested the questionnaire among 180 HCPs in another tertiary care hospital. 146 participants responded. $68 \%$ doctors, $28 \%$ nurses and $14 \%$ nursing students had injury in the last 12 months $[P<0.001]$. The mean number of injuries was 3 i (SD 1.23) $[P=0.009$, one-way ANOVA]. After the pretesting, minor changes in the questionnaire were made.

\section{Definitions}

Sharps injury- Any cut or prick to the respondents by a sharp object (needle, glass, lancet or surgical instrument) previously used on a patient, is work related and sustained within the hospital premises.

Splash - Any contact of the body with patient's blood or body fluids.

\section{Survey method and ethical issues}

The authors conducted the cross-sectional survey. The purpose of the study was explained verbally in English to each participant and the questionnaire was distributed after taking written consent. Participants were instructed not to write their names or identify themselves or their institution in any way. A single list was made in order to maintain the anonymity of the hospitals. Some of the respondents completed the forms right away while some others preferred to complete them during their free time and turned them in after a few days. Failure to return the questionnaires even after three verbal, personal reminders was considered as 'non-response'. Data was entered in Microsoft Excel and analyzed using SPSS for Windows version 11. The statistical tests used to assess the strength of association between two variables included Chi square test, independent-sample T test and one-way ANOVA. The outcome variables were tested for association with five predictor variables (occupation category, sex, training, immunization and experience). If a dependent variable was associated with more than one independent variable, multivariate analysis by binary logistic regression was undertaken to control for possible confounders.

\section{RESULTS}

\section{Demographic characteristics}

A total of 755 questionnaires were distributed with a response rate (RR) of $65 \%$. Mean age of the respondents was 32.09 years (range 20-45 years; $\mathrm{SD}_{1}$ 10.3), majority of them being females (71\%). The respondents included 180 surgeons (RR-59\%), 90 anesthetists (RR-44\%), 350 nurses (RR-64\%), 60 medical students (RR-85\%) and 75 nursing students (RR-96\%).

\section{Perception, exposure and post exposure}

A majority of the participants (85\%) were concerned about acquiring blood borne infection and an equal number of them also believed that sharps injuries were avoidable. Approximately half the number of respondents perceived that needle injury was part of their job (Table 1). A fairly large number of respondents (83\%) were well informed that Hepatitis B poses the maximum risk of transmission on exposure to blood or body fluids.

The extent of exposure was disturbingly high, with the mean number of sharps injuries being 2.8 and splash, 3.3 (Table 2). Three quarters of the respondents (95\% CI 71.3 to 78.2) were exposed at least once in the last 12 months (Table 3). Analyzing the circumstances of injury, we found that surgeons were most often injured while performing surgery (65\%). Anesthetists were stuck while breaking a vial (47\%) and so were nurses (33.5\%). For nursing students, recapping (55\%) led to most injuries and for medical students, it was suturing (34\%). Most of the injuries occurred in the emergency room (36\%) and 
Table 1: Perception of risk of occupational exposure $(n=495)$

\begin{tabular}{|c|c|}
\hline Response & $\%$ Yes (n) \\
\hline \multicolumn{2}{|l|}{ Perception about exposure } \\
\hline I believe that needle injuries are part of my job. $(n=473)$ & $50.5(239)$ \\
\hline I believe that needle injuries are avoidable $(n=486)$ & $87.2(424)$ \\
\hline Concern about blood borne infection $(n=389)$ & $85.1(331)$ \\
\hline \multicolumn{2}{|l|}{ Knowledge } \\
\hline Hepatitis B has the maximum risk of transmission & $82.5(391)$ \\
\hline Hepatitis $C$ has the maximum risk of transmission & $5.5(26)$ \\
\hline HIV has the maximum risk of transmission & $12(57)$ \\
\hline $\begin{array}{l}\text { Do you know if post exposure prophylaxis is provided by your } \\
\text { institute? }(n=369)\end{array}$ & $39(144)$ \\
\hline Universal precautions & \\
\hline $\begin{array}{l}\text { Was there shortage of disposable syringes at any time in } \\
\text { last } 12 \text { months? }(n=452)\end{array}$ & $17.9(81)$ \\
\hline $\begin{array}{l}\text { Was there shortage of gloves at any time in last } 12 \\
\text { months? }(n=469)\end{array}$ & $30.5(143)$ \\
\hline $\begin{array}{l}\text { Containers are available where and when I need them to } \\
\text { dispose of needles and other sharp devices }(n=483)\end{array}$ & $81.8(395)$ \\
\hline $\begin{array}{l}\text { Problems that increase the risk of sharp injuries are quickly } \\
\text { corrected once they are brought to hospital authority's } \\
\text { attention }(n=426)\end{array}$ & 475 (238) \\
\hline
\end{tabular}

Table 2: Mean number of injuries and splash per person per year, for those injured one or more times

\begin{tabular}{lcc}
\hline Occupation group & Mean (S.D) Injury & Mean (S.D) Splash \\
\hline Surgeons & $3.8(3.6)$ & $3.4(2.9)$ \\
Anesthetists & $2.9(1.6)$ & $4.0(3.6)$ \\
Nurses & $1.87(1.0)$ & $3.1(2.4)$ \\
Medial students & $1.9(1.2)$ & $3.3(3.0)$ \\
Nursing students & $1.9(0.7)$ & $2.4(1.3)$ \\
Total & $2.8(2.6)$ & $3.3(2.7)$ \\
\hline
\end{tabular}

Table 3: Extent of exposure according to occupation groups

\begin{tabular}{lccc}
\hline Occupation & $\begin{array}{c}\text { Percutaneous } \\
\text { exposure } \\
\text { (Sharps injury) }\end{array}$ & $\begin{array}{c}\text { Mucocutaneous } \\
\text { exposure (Splash) }\end{array}$ & Exposure* \\
\hline Surgeons & $84(83.2)$ & $93(91.2)$ & $98(93.3)$ \\
Anesthetists & $25(67.6)$ & $31(79.5)$ & $34(85.0)$ \\
Nurses & $87(41.2)$ & $129(60.6)$ & $155(68.9)$ \\
Medical students & $14(29.2)$ & $28(57.1)$ & $33(66.0)$ \\
Nursing students & $16(25.0)$ & $43(63.2)$ & $45(64.3)$ \\
Total percentage & $226(49.0)$ & $324(68.8)$ & $365(74.5)$ \\
$P$ value & $<0.001$ & $<0.001$ & $<0.001$
\end{tabular}

"Exposure is defined as any contact with patient's blood and body fluids, percutaneous or mucocutaneous, Figures in the parenthesis are in \%.
Operation Theater (34\%).

Inattention from hospital authority was evident when more than half of the respondents disagreed to the statement that problems that increase the risk of sharp injuries were quickly corrected once they were brought to the hospital authority's attention. The participants also described an acute shortage of syringes and gloves (Table 1). Knowledge about availability of a service is the first step toward its utilization. But it was found that only $39 \%$ of the respondents knew that their institute provided PEP.

\section{Correlates of exposure}

Occupation, experience, sex, training and concern for blood borne infections were found to be associated with injury.

\section{Occupation}

We found a strong association between occupation and injury; surgeons and anesthetists were exposed considerably more than the other groups (Table 3). The mean number of injuries was also higher in these two groups (Table 2) (One way ANOVA, $P$ value 0.012). Table 4 presents the chi-square values for associations between the outcome and predictor variables, the latter being experience, sex, training and concern for blood borne infections.

\section{Experience}

We found that as experience is increasing, incidence of injury is decreasing. $61 \%$ of respondents belonging to the $1-10$ years experience group were injured, 56\% in the 11-20 years group and $46 \%$ in the group with more that 20 years' experience.

\section{SeX}

Male sex was found to be another risk factor. Proportionately more number of males (63\%) were injured than females (43\%). The mean number of injuries in males, 3.6 (S.D. 3.5) was more than in females, 2 (S.D. 1.2). A large proportion of respondents were immunized against hepatitis $B$, male $96.4 \%(n=135)$ and female $88.5 \%(n=299)(P$ value $=0.005$. odds ratio $=3.5,95 \%$ $\mathrm{CI}=1.35$ to 9.13 ). We wondered why more men were injured.

Table 4: Correlates of exposure

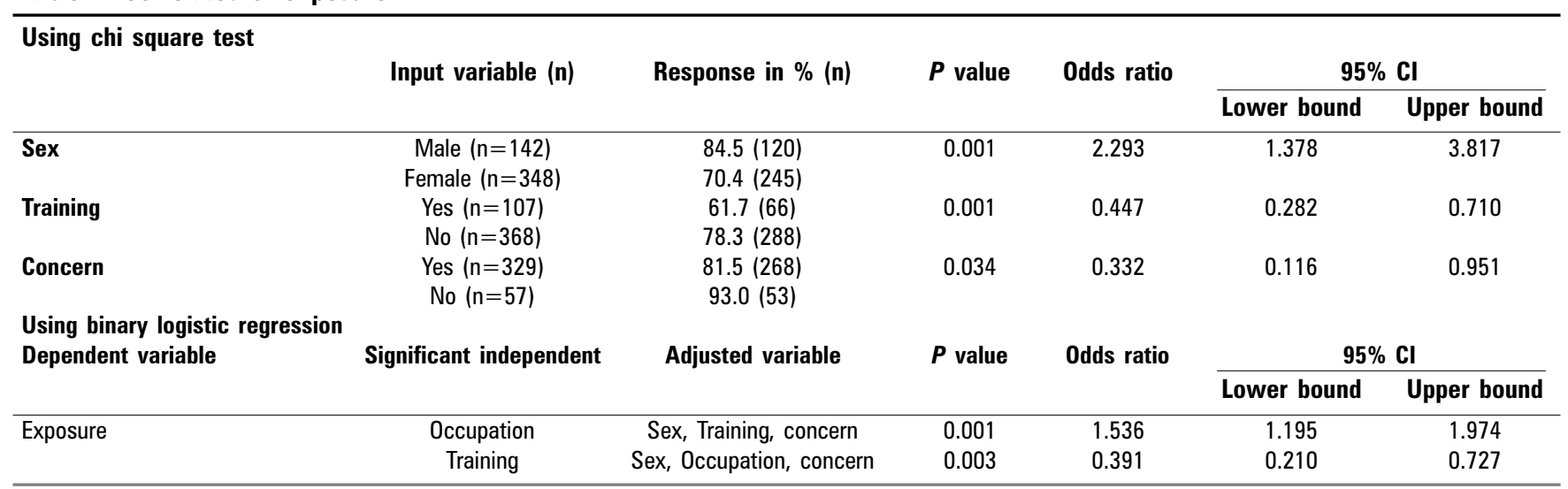


Was it simply because of their sex or because more males were immunized and were probably less careful about injuries. On further analysis of only immunized respondents, we again found that the ratio of injured males and females was almost 2 (odds ratio $2.479,95 \% \mathrm{CI}=1.435$ to $4.281, P$ value 0.001 .) The mean number of injuries among immunized males was $3.69(\mathrm{~S} . \mathrm{D}=3.6)$ and that among immunized females was $2.07(\mathrm{~S} . \mathrm{D}=1.89)$.

\section{Training}

The needle safety-training program, although lasting only ten hours per year, was found to have a positive impact. Exposure was less (62\%) among those trained than among those not (78\%). Unfortunately, only $22 \%(n=479)$ of respondents were trained, including $4 \%$ surgeons, $5 \%$ anaesthetists, $42 \%$ nurses, $2 \%$ medical and $13 \%$ nursing students. There was considerable ignorance about exposure reporting procedure. The three main reasons for not reporting the exposure were that they did not know the reporting procedure (28\%), some thought the type of exposure was low risk (28\%), and some did not think it was important to report (26\%) (Table 5). After controlling for age, experience, sex and a range of variables (using multiple regression analysis), occupation group and training emerged as the most important predictor variables for exposure (Table 4).

\section{DISCUSSION}

Health care providers in the three tertiary care centers studied were certainly at risk for occupational injury. Males, surgeons and HCP immunized against HBV had higher number of injuries. Female sex, concern for exposure and training was associated with lower injury.

This study has looked at the health care providers' perception of risk of occupational exposure to blood borne infections and has compared the exposure across five different categories of HCP. Previous studies from India and US analyzed exposure in a single type of HCP. ${ }^{[7,8]}$ We compared exposure across five different groups to determine where, how and when injuries were occurring. According to the WHO, nurses are the group most at risk in any health care establishment. ${ }^{\left[{ }^{[9}\right.}$ In contrast, we found that surgeons were at highest risk, followed by anesthetists. Both the groups sustained an alarmingly high number of injuries (Table 2). 62.5\% of the anesthetists in our study were injured compared to $39 \%$ in an Australian study. ${ }^{[10]}$ Injuries among students were disturbingly high. 65\% of medical students were exposed at least once when compared to $27 \%$ in a study in the U.S. ${ }^{[11]}$ The pattern of high number of injuries was seen also among nurses in our study. Almost $70 \%$ of nurses had at least one exposure, which is much higher than the $9 \%$ found in a previous study. ${ }^{[12]}$ A high degree of dual burden of exposure was also noticed among all groups, as the majority of those injured (87\%) were also splashed during the same period.

In analyzing the work practices, we found that one-third of injuries were due to recapping needles, compared to $5 \%$ in the study of US health care workers. ${ }^{[13]}$ While surgeons sustained most injuries with a suture needle, the injection needle was responsible for most injuries in all other groups. Approximately three-quarters of injuries occurred in the emergency room and in operation theaters. Reasons for this need to be further examined to find out if high patient load, insufficient staff or other reasons peculiar to these locations was the cause for increased injury, or just greater exposure. We found that more experienced HCP sustained fewer injuries. A similar finding was reported in a study done on nurses in the U.S. ${ }^{[12]}$ Students (both medical and nursing) had lower injury rates but also spent less time in patient care than doctors or nurses.

We tried to understand the association between concern for blood borne infection and exposure. Why were fewer surgeons and anesthetists concerned when compared to nurses and students? The former category is predominantly male. Are they less risk averse? (Men were injured almost twice as often as women). Or are they complacent because almost all of them were immunized against HBV? But, even among the immunized, men were injured almost twice as often as women.

Universal precautions (U.P) mean that body fluids of all patients should be treated as infectious. ${ }^{[14]}$ Contrary to this, we found that only those patients admitted for surgery were screened for HIV antibody and HBsAg. Anecdotal evidence gathered from informal conversations with several HCP revealed that U.P were followed only if the test result was

Table 5: Reasons for not reporting the exposure (In percentage)

\begin{tabular}{lccccc}
\hline Occupation (n) & $\begin{array}{c}\text { No time } \\
\text { to report }\end{array}$ & $\begin{array}{c}\text { Don't know the } \\
\text { reporting procedure }\end{array}$ & $\begin{array}{c}\text { Worried about } \\
\text { confidentiality }\end{array}$ & $\begin{array}{c}\text { May be blamed } \\
\begin{array}{c}\text { Low risk } \\
\text { for infection }\end{array}\end{array} \begin{array}{c}\text { Not important } \\
\text { to report }\end{array}$ \\
\hline Surgeons (79) & 15.2 & 48.1 & 0 & 1.3 & 22.8 \\
Anaesthetists (34) & 11.8 & 44.1 & 2.9 & 2.9 & 50 \\
Nurses (123) & 21.1 & 11.1 & 11.4 & 7.3 & 20.3 \\
MBBS (31) & 6.5 & 45.2 & 3.2 & 3.2 & 26.8 \\
Nursing students (43) & 14 & 14 & 4.7 & 11.6 & 3.6 \\
Total (310) & 16.1 & 28.1 & 5.8 & 5.5 & 32.6 \\
\hline
\end{tabular}

(Multiple responses possible and hence do not add up to $100 \%$ ) 
positive. Although the setting was tertiary care hospitals, U.P were being compromised, as evident from shortage of gloves (Table 1) Once injured, respondents did not know whom to contact. This is not new and similar findings were reported previously from India. ${ }^{[15]}$ It is important to find out why especially the medical staff did not know the reporting procedure (Table 5). The absence of reporting procedure was probably the reason for the confusion. ${ }^{[16,17]}$ Surgeons and nurses mentioned that they did not have the time to report. It is imperative to have a simple reporting format so as to not to add to their burden in terms of time constraints. Students, (both medical and nursing) thought that it was not important to report. This could have serious consequences and efforts should be focused on students to dispel such misinformation. As found in two other studies in India, there is surprisingly poor knowledge about PEP services, ${ }^{[18,19]}$ as evident from the finding that only $39 \%$ knew that their institutes provided PEP. After exposure, only one in four respondents was tested for blood borne infections.

Exposure was inversely related to training. Few providers, except nurses, underwent a needle safety-training program in their hospital. Even then, a sizeable number of those trained were subsequently exposed. Was the training program too non-specific? Why were the medical professionals like surgeons, anesthetists and MBBS students not included in training programs? Anecdotal sources in our study pointed out at least 3 incidents of occupational exposure leading to confirmed infection. In the absence of surveillance systems, especially in developing countries, it is difficult to estimate the number of HCP who have acquired occupational blood borne infections. For the same reason, it will be hard to find out if prevention strategies are working, and if injuries are reducing with time.

Analysis of the HCP perceptions brought to light the behavioral aspects that play a role in injuries. Although half of the respondents believed that needle injuries are part of their job, almost all of them believed that they are avoidable. It was also encouraging to note that nine out of ten respondents were immunized against Hepatitis B. It seems they are concerned about blood borne infections and would likely be receptive to the introduction of policies that highlight safety procedures for reduction of injury.

There are limitations to the study, which include the following: A sizeable number of respondents were unable to recollect the number of injuries. Some exposures were described as "infinite", "stopped counting", "more than 500", "daily". Although such responses were deleted from the analysis in order to avoid skewing of the results, the reasons for such answers may bring out new aspects of health care providers' behavior.

\section{CONCLUSIONS}

Setting up an effective injury surveillance system in developing countries is essential to safe guard the health of the providers. Policies addressing information dissemination and exposure reporting should be introduced immediately. Intense and regular training sessions should be conducted for all staff and students, taking into account the varying incidence of exposure among different occupation groups. Most importantly, the exposure-reporting format should be made simple in order to encourage reporting by HCP who are hard pressed for time.

\section{ACKNOWLEDGEMENTS}

The authors wish to express their gratitude to Dr. P. Sankara Sarma (Additional Professor, Sree Chitra Tirunal Institute for Medical Sciences and Technology) for the general support and technical guidance. The authors are also grateful to Dr. Richard A. Cash (Senior Lecturer, Harvard School of Public Health), for the constant motivation and for critically reviewing the article.

\section{REFERENCES}

1. Gyawali P, Rice PS, Tilzey AJ. Exposure to blood borne viruses and the hepatitis B vaccination status among healthcare workers in inner London. Occupational Environmental Medicine 1998;55:570-2.

2. WHO. Reducing Risks, Promoting Healthy Life. The world health report 2002. Geneva: World Health Organization; 2002.

3. Moloughney WB. Transmission and post exposure management of bloodborne virus infections in the health care setting: Where are we now? Canadian Medical Association Journal 2001;165:445-51.

4. Sagoe-Moses C, Pearson RD, Perry J, Jagger J. N Engl J Med 2001;345.

5. Sharps injury control program report. Department of health services, California. January 2002. [Cited on 2005 November 7]. Available from http://www.sharpslist.org/assets/forms/Sharps_Report.pdf

6. CDC. Workbook for Designing, Implementing, and Evaluating a Sharps Injury Prevention Program. United States. Centers for Disease Control and Prevention; February 2004.

7. Shen C, Jagger J, Pearson RD. Risk of needle stick and sharp object injuries among medical students. Am J Infect Control 1999;27:435-7.

8. Varma M, Mehta G. Needle stick injuries among medical students. Journal of the Indian Medical Association 2000;98:436-8.

9. WHO. Safe Management of Wastes from Health Care Activities. Geneva. World Health Organization; 1999.

10. Richards MJ, Jenkin GA, Johnson PD. Universal precautions: attitudes of Australian and New Zealand anaesthetists. Medical Journal Australia. 1997;166:138-40.

11. Osborn HSE, Papadakis MA, Gerberding JL. Occupational exposure to body fluids among Medical Students, A seven Year Longitudinal Study. Annals Of Internal Medicine 1999;130:45-51.

12. Clarke SP, Rockett JL, Sloane DM, Aiken LH. Organizational climate, staffing, and safety equipment as predictors of needlestick injuries and near misses in hospital nurses. Am J Infect Control 2002;30:207-16.

13. NIOSH. Alert, Preventing Needlestick Injuries in Health Care Settings, DHHS (NIOSH) November 1999.

14. WHO. Prevention of HIV transmission in a health care setting. In: Infection control. Geneva: World Health organization; 1993:12-3.

15. Chogle NL, Chogle MN, Divatia JV, Dasgupta D. Awareness of postexposure prophylaxis guidelines against occupational exposure to HIV 
in a Mumbai hospital. Natl Med J India 2002;15:69-72.

16. Karstaedt AS, Pantanowitz L. Occupational exposure of interns to blood in an area of high HIV seroprevalence. S Afr Med 2001;91:57-61.

17. Haiduven DJ, Simpkins SM, Phillips ES, Stevens DA. A survey of percutaneous/mucocutaneous injury reporting in a public teaching hospital. J Hosp Infect 1999;41:151-4.
18. Varghese GM, Abraham OC, Mathai D. Post-exposure prophylaxis for blood borne viral infections in healthcare workers, Postgrad Med J 2003;79:324-8.

19. Gounden YP, Moodley J. Exposure to Human Immunodeficiency Virus among Healthcare workers in South Africa. Int J Gynaecol Obstet 2000;69:265-70. 